\title{
Drug ampoules in rectum: Lucky co-incidental finding in emergency department of eastern Nepal
}

\author{
S Giri ${ }^{1}$, R Gupta ${ }^{2}$, R Bhandari ${ }^{3}$ S Chaudhuri ${ }^{4}$
}

Department of General Practice and Emergency Medicine, B.P. Koirala Institute of Health Sciences

\begin{abstract}
Background: Rectal foreign body is uncommon in emergency usually presenting after failure to remove the object manually or with other complications. Case: Twenty two years male in emergency department presented with rectal bleeding following a manual attempt to remove drug ampoules from rectum. Conclusion: In an unexplained rectal bleed, foreign bodies could be a pitfall.
\end{abstract}

Keywords: Drug ampoules, emergency, foreign body rectum.

\section{Introduction}

Rectal foreign body isan uncommon presentation in emergency departments (ED) in Asia. ${ }^{1,2}$ Most of the cases reported are from the eastern Europe. ${ }^{1,2}$ Hardly any cases could be found reported from Nepal. The common etiology aranal autoeroticism, concealment, accidental event, assault, attention-seeking behavior, and aid to alleviate constipation. The most common cause of insertion of foreign body is eroticism. ${ }^{3}$ The most commonly used foreign body is household objects consisting of bottles and glasses $(42.2 \%)$ followed by toothbrushes, deodorant

\section{Address for correspondence}

Dr. Saroj Giri

Assistant Professor

Department of GP and EM

B.P. Koirala Institute of Health Sciences, Dharan

E-mail:dr.sarojgiri@gmail.com bottles, food articles, knives, sports equipment, cell phones, flashlights, wooden rods, broomsticks, sex toys including dildos and vibrators, light bulbs, nails or other construction tools. ${ }^{4}$ Furthermore, insertion of drug ampules in rectum for the purpose of 'body-packing' has not been reported from Nepal. It is mainly used for carrying heroin, cocaine, amphetamines, and cannabis. Body packers usually present to the emergency department because of drug toxicity, intestinal obstruction, or more commonly, requested by police for medical confirmation or exclusion of suspected body packing ${ }^{5}$. We report a case of drug ampules as foreign body in rectum encountered in a tertiary care hospital in Nepal. 


\section{Case report}

A 22-year-old unmarried male presented to emergency department, with complain of bleeding per rectum. On probing he gave history of inserting five ampoules of injection diazepam per rectum. He was travelling across the India-Nepal border to Dharan, Nepal. When he tried to extract the lowest lying ampule, it broke followed by bleeding per rectum. He had previous successful attempts of extraction of drug ampules from his anus without any complications.

On presentation, he appeared anxious. He was fully conscious and oriented. Vitals were within normal limits. Physical examination was unremarkable. Cardiopulmonary and abdominal examinations were normal, and there were no signs of drug intoxication or overdose. On local examination, stain of blood was noted around anal opening. Digital rectal examination was not done. A plain abdominal radiograph showed four ampule on left lower quadrant along the gastrointestinal tract (Figure 1). Blood investigations were also within normal limits. Patient refused further investigations.

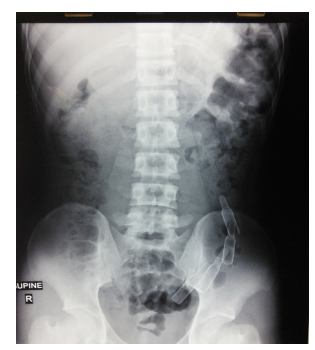

Figure 1
He was counseled for the need of surgical consultation and exploration under general anaesthesia but he refused. Lignocaine jelly about $200 \mathrm{ml}$ was instilled per rectum to alleviate pain. After about 15 minutes patient had urge for defecation. He passed all the ampules unbroken. Check x-ray was advised but the patient absconded immediately after passage of drug ampules in the toilet.

\section{Discussion}

Rectal foreign body is uncommon presentation in emergency in Asia. ${ }^{1,2} \mathrm{~A}$ case report by Spanager et al suggested that most of the cases presenting in emergency are either after failure to remove the object manually or if there is bleeding. ${ }^{6}$ However, the chances of occurrence of complications is $<1 \%{ }^{6}$ In case of 'body packers', ED presentations were due to drug toxicity, intestinal obstruction, or more commonly, requested by police for medical confirmation or exclusion of suspected body packing. ${ }^{5}$ History is a cornerstone of suspicion. Physical and systemic examination should be focused on features of hemorrhagic shock, GI tract obstruction or perforation, peritonitis and features of intoxication in case of body packing. Plain abdominal radiograph and per rectal examination are usually diagnostic. Low lying anal foreign body is usually removed transanally, whereas high-lying foreign bodies may require exploration under 
general anaesthesia. ${ }^{7,8}$ Management also depends upon the nature of object inserted. Following the diagnosis, various studies have suggested that attempts to remove foreign body atemergency room or bedside is initially preferred $^{2}$. Transanal route is the first choice of extraction especially in case of low lying objects butbefore the procedure, acute abdomen should be ruled out. The success rate of emergency department attempts ranges from 16 to $75 \%$ in different literatures. $^{2}$

\section{Conclusion}

The drug ampoules as foreign body, gave us an opportunity to explore the possibility of "body packing" or a simple example of "Eroticism". Hence as emergency physicians, we should have high index of suspicion with young males, suspected intravenous drug users and abnormal clinical presentation at emergency. Management of these patients is a medical challenge where legal issues also play an important role.

\section{References}

1. Akhtar MA., Arora PK.. Case of Unusual Foreign Body in the Rectum. The Saudi Journal of Gastroenterology 2009 15(2): 131-2

2. Yildiz SY, Kendirci M, Akbulut S, Ciftci A, Turgut HT and Hengirmen S. Colorectal emergencies associated with penetrating or retained foreign bodies. World Journal of Emergency Surgery 2013, 8:25

3. Azman B, Burak Erku Z, Haluk B Gu ven 0; Balloon Extraction of a Retained Rectal Foreign Body Under Fluoroscopy, Case Report and Review. Pediatr Emer Care 2009;25: 345-347

4. Cologne, KG, Ault GT.,: Rectal Foreign Bodies: What Is the Current Standard? . Clin Colon Rectal Surg. 2012; 25(4): 214218.

5. Wong GCK, Lai KK, Chung $\mathrm{CH}$. Management of body packers in the emergency department. Hong Kong Journal of Emergency Medicine. 2005;12(2):112-118.

6. Spanager L, Mohr M. An unusual case of a screwdriver found in rectum. Ugeskr Laeger. 2011;173(49):3190-1

7. Feigelson S, Maun D, Silverberg D, Menes $T$. Removal of a large spherical foreign object from the rectum using an obstetric vacuum device: a case report. Am Surg. 2007; 73(3):304-6.

8. Coskun A, Erkan N, Yakan S, Yıldirim M and Cengiz. Management of rectal foreign bodies; World Journal of Emergency Surgery 2013, 8:11 doi: 10.1186/17497922-8-11. 